\title{
Periodontoid Synovial Cyst Causing Cervico-medullary Compression
}

\author{
Anthony M. Kaufmann, William C. Halliday, Michael West, \\ Derek Fewer and Ian Ross
}

\begin{abstract}
Background: Periodontoid synovial cysts are rare lesions which may produce symptomatic cervico-medullary compression. Method: We report such a patient, whose progressive neurological deterioration required surgical treatment by transoral odontoidectomy and decompression. Results: The diagnostic and theraputic interventions are described, including a lumbar puncture which precipitated a transient loss of consciousness and respiratory arrest. Surgery achieved clinical improvement, without complications or need for operative stablization. Detailed neuropathology is presented, as well as a literature review. Conclusion: Appropriate neuroradiological assessment is required in patients with suspected cervico-medullary compression, and symptomatic periodontoid synovial cysts may respond well to transoral surgical decompression.
\end{abstract}

\begin{abstract}
RÉSUMÉ: Kyste synovial périodontoïde causant des compressions cervicomédullaires. Introduction: Les kystes synoviaux périodontoïdes sont des lésions rares qui peuvent causer des compressions cervicomédullaires symptomatiques. Méthodes: Nous rapportons le cas d'un patient présentant une détérioration neurologique progressive qui a du être traité chirurgicalement par odontoïdectomie transorale et décompression. Résultats: Nous décrivons les interventions diagnostiques et thérapeutiques, dont la ponction lombaire compliquée d'une perte de conscience transitoire et d'un arrêt respiratoire. La chirurgie a amené une amélioration clinique sans complication et sans stabilisation opératoire. Nous présentons un rapport neuropathologique détaillé ainsi qu'une revue de la littérature. Conclusions: Les patients chez qui on soupçonne une compression cervico-médullaire doivent subir une évaluation neuroradiologique appropriée. La décompression chirurgicale transorale peut donner de bons résultats dans les kystes périodontoïdes symptomatiques.
\end{abstract}

Can. J. Neurol. Sci. 1996; 23: 227-230

Spinal synovial cysts have been rarely reported at the atlantoaxial level 1.2 .3 We present the history, neuroradiology, and histopathology of a periodontoid synovial cyst in a patient presenting with extradural spinal cord compression. The relevant literature is reviewed and the disease process is discussed.

\section{Case History}

This 52-year-old man was referred to the neurosurgery service with a long history of progressive neurological complaints. He described intermittent limb numbness and episodes of neck pain for two years. There was no history of trauma. An exacerbation of neck pain was associated with severe gait ataxia and slurred speech. The patient's condition then dramatically deteriorated. He developed pneumonia and sepsis, leading to admission to a peripheral hospital. After a cranial computerized tomographic (CT) scan was found to be normal, cerebral spinal fluid was obtained by lumbar puncture. This demonstrated an elevated opening pressure, elevated protein, and an elevated white cell count, but no bacteria. The procedure precipitated a brief loss of consciousness and respiratory arrest from which the patient was quickly resuscitated without further sequelae. During the following week his general condition improved but the limb ataxia recurred.

The patient was then transferred, and admitted to the neurosurgical service. His neurological examination disclosed an asymmetrical palate, absent gag reflex, and weak sternocleidomastoid muscles. The cranial nerves were otherwise normal. His limbs were moderately weak, more so on the right side. He demonstrated bilateral hyperreflexia, Hoffmann and Babinski signs, and absent abdominal and cremasteric reflexes. There was symmetrical wasting of the intrinsic hand muscles with fasciculations. All peripheral sensory modalities were diminished with relative sacral sparing, and sensory ataxia was apparent. He required assistance to stand, while gait was wide based and stiff. A medical and rheumatological work-up did not disclose any underlying systemic disease.

A CT myelogram done previously was reviewed and although the contrast column did not reach the foramen mannum, posterior displacement of the cervical medullary junction was evident. Magnetic resonance imaging (MRI) demonstrated a large retro-odontoid cystic lesion causing displacement and compression of the cervical medullary junction (Figure la). Increased signal intensity of the spinal cord indicated secondary edema or demyelination. The odontoid process appeared normal, while the periodontoid ligaments were thickened and contributed to the mass effect. Radiographs demonstrated subluxation of the atlantoaxial segment (Figure 3a).

From the Section of Neurosurgery, (AMK, MW, DF, IR) and the Department of Pathology (WCH), University of Manitoba.

RECEIVED APRIL, 28, 1995. ACCEPTED IN FINAL FORM MARCH 20, 1996

Reprint requests to: Anthony M. Kaufmann, M. D., Assistant Professor, Department of Neurological Surgery, University of Pittsburgh. Suite B-400, 200 Lothrop Street Pittsburgh PA 15213-2582, U.S.A. 


\section{ManaGement}

An anterolateral CT-guided percutaneous needle biopsy of the periodontoid lesion was performed. Adequate tissue specimens could not be obtained; however, $10 \mathrm{cc}$ of mucinous fluid were aspirated. This contained no infectious or neoplastic elements. MRI following aspiration showed significant reduction of the cyst volume and less cord compression.

The patient initially improved following the cyst aspiration, in conjunction with parenteral Decadron and vertical immobilization with a semirigid collar. However, he experienced continued exacerbations of neck pain with increased numbness and ataxia. It was elected to proceed with surgical decompression of the periodontoid mass lesion. An anterior transoral approach was employed with removal of the anterior atlantal arch, odontoid process, and surrounding abnormal tissue mass (Figure lb). A fusion was not performed. There were no operative complications and subjective improvement of sensation was reported. The patient was discharged from hospital on the eighth postoperative day, wearing a semirigid cervical collar. Three months later, he had continued to make moderate neurological improvement. At that time he was independent in activities of daily life, and walking with the assistance of a cane. Flexion and extension cervical radiographs were repeated and disclosed no instability, despite surgical fusion not having been performed (Figure 3b).

\section{Histopathology}

The specimen consisted of multiple fragments of a gritty grey-white tissue that required brief decalcification. Microscopic examination revealed bone, cartilage and fibrous ligamentous tissue. The latter showed areas of scattered clefts and fissures adjacent to the bony ligamentous insertion. In addition, within the ligamentous tissue there were cysts containing an amorphous material (Figure 2a). Adjacent to the degenerative cysts and ligamentous tissue, there were areas of established fibrovascular tissue. Focally, a synovial-like lining was noted while most of the cysts had no lining (Figure $2 b$ ). These findings of ligamentous degenerative cyst formation and partial regenerative cyst lining indicated the diagnosis of synovial cyst or ganglion.

\section{Discussion}

\section{Presentation}

Intraspinal masses at the cervical-medullary junction result in a unique and potentially confusing clinical presentation. Compression of the decussating fiber tracts produces variable and often fluctuating motor and sensory deficits. The symptoms may suggest a diagnosis of multiple sclerosis, motor neuron disease or vertebro-basilar vascular insufficiency. Clues to the correct

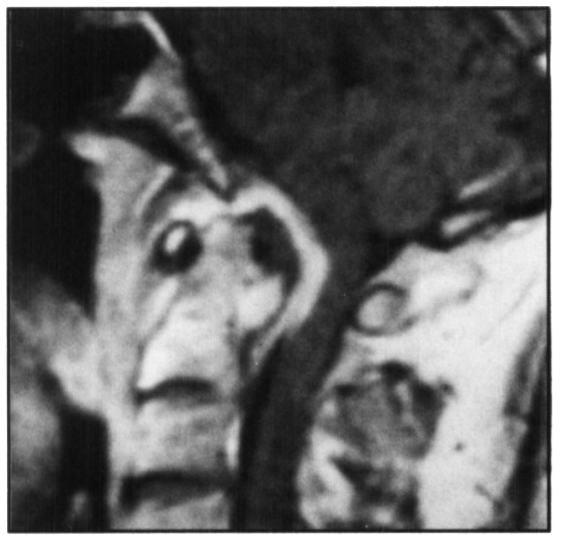

Figure 1a: This sagittal $T$, weighted MRI demonstrates a large retroodontoid cystic lesion, which causes displacement and compression of the cervical medullary junction. The periodontoid ligaments are thickened and contribute to the mass effect.

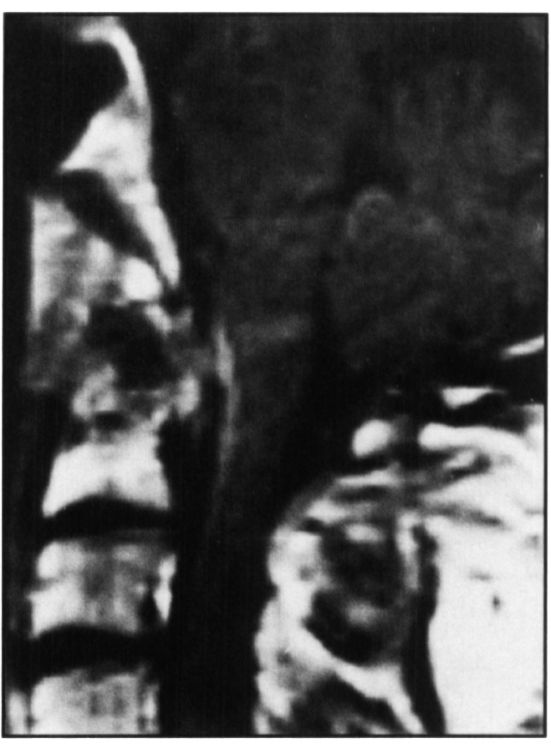

Figure Ib: Three months postoperatively the MRI demonstrates resection of the anterior atlantal arch, odontoid process and synovial cyst. Cervical-medullary junction decompression was achieved, with improvement of neurological function.

diagnosis include a history of neck pain and involvement of the lower cranial nerves or upper cervical roots. The pneumonia in our patient was likely secondary to the lower cranial nerve palsies and resulting aspiration. Intrinsic hand wasting in association with upper cervical cord compression has been previously described, and may be related to vascular insufficiency from compression of the anterior spinal artery..$^{3,4,5,6}$

The loss of consciousness and respiratory arrest immediately following removal of CSF by lumbar puncture presumably was due to increased compression or distortion of the cervicomedullary respiratory centres, resulting from the altered CSF pressure dynamics.

\section{Histopathology}

Synovial cysts of the spine most commonly arise at the facets of the lumbar and cervical spine. ${ }^{7-15}$ These cysts have also been demonstrated in relation to other paraspinal ligaments, including ligamentum flavum, ${ }^{16,17,18}$ interspinous ligament ${ }^{19}$ and the anterior longitudinal ligament. ${ }^{20}$ Rarely synovial cysts have been reported in the periodontoid region. , 2,3 The paraspinal "synovial" cysts typically are not lined by synovium and therefore the term ganglion cyst has also been applied more accurately. ${ }^{21,22}$

Several possible etiologies have been proposed to account for the formation of spinal synovial cysts or ganglions. ${ }^{7,11,23-26}$ These include facet stress and synovial herniation, cellular metaplasia, and proliferation of developmental rests of ectopic synovial tissue. However the explanation most in keeping with histopathological observations involves degenerative changes of the ligamentous tissue with secondary cyst formation. The histopathology in our case involved definite degenerative changes. The periodontoid ligaments demonstrated fracturing and cleft formation with apparent coalescence to form larger cysts, which were partially lined by synovial-like cells.

The synovial cyst we describe was associated with thickening of the periodontoid ligaments. The histopathological correlate of this was degenerative changes of the ligaments and secondary 


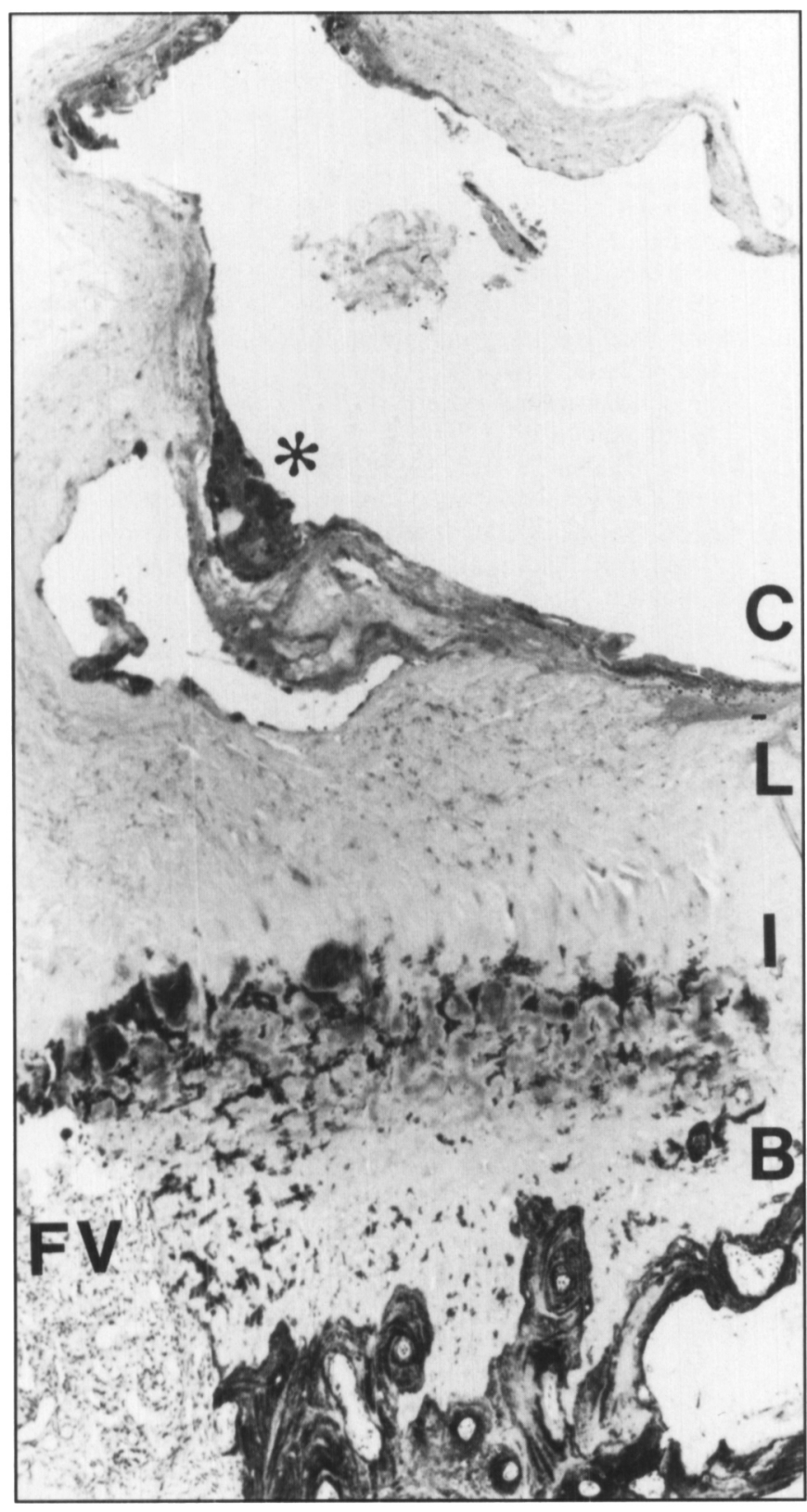

Figure 2a: This photo micrograph demonstrates bone (B), ligamentous insertion (I), and ligament $(L)$. Cystic spaces $(C)$ are evident within the ligament, and contain amorphous material $\left({ }^{*}\right)$. An area of reactive fibrovascular tissue is also seen (FV).

reactive fibrovascular tissue. Similar periodontoid mass lesions, without cysts, have been described in patients with variable degrees of atlantoaxial instability. ${ }^{27,28}$ This is in keeping with the notion that the fibrovascular granulation tissue is reactive and thus may have a number of different etiologies.

\section{Management}

In our patient conservative management produced only partial and transient improvement. Furthermore, percutaneous cyst aspiration did not produce diagnostic tissue. Definitive surgical intervention provided both diagnostic histopathology as well as decompression of the spinal cord.

The choice of surgical approach to periodontoid mass lesions

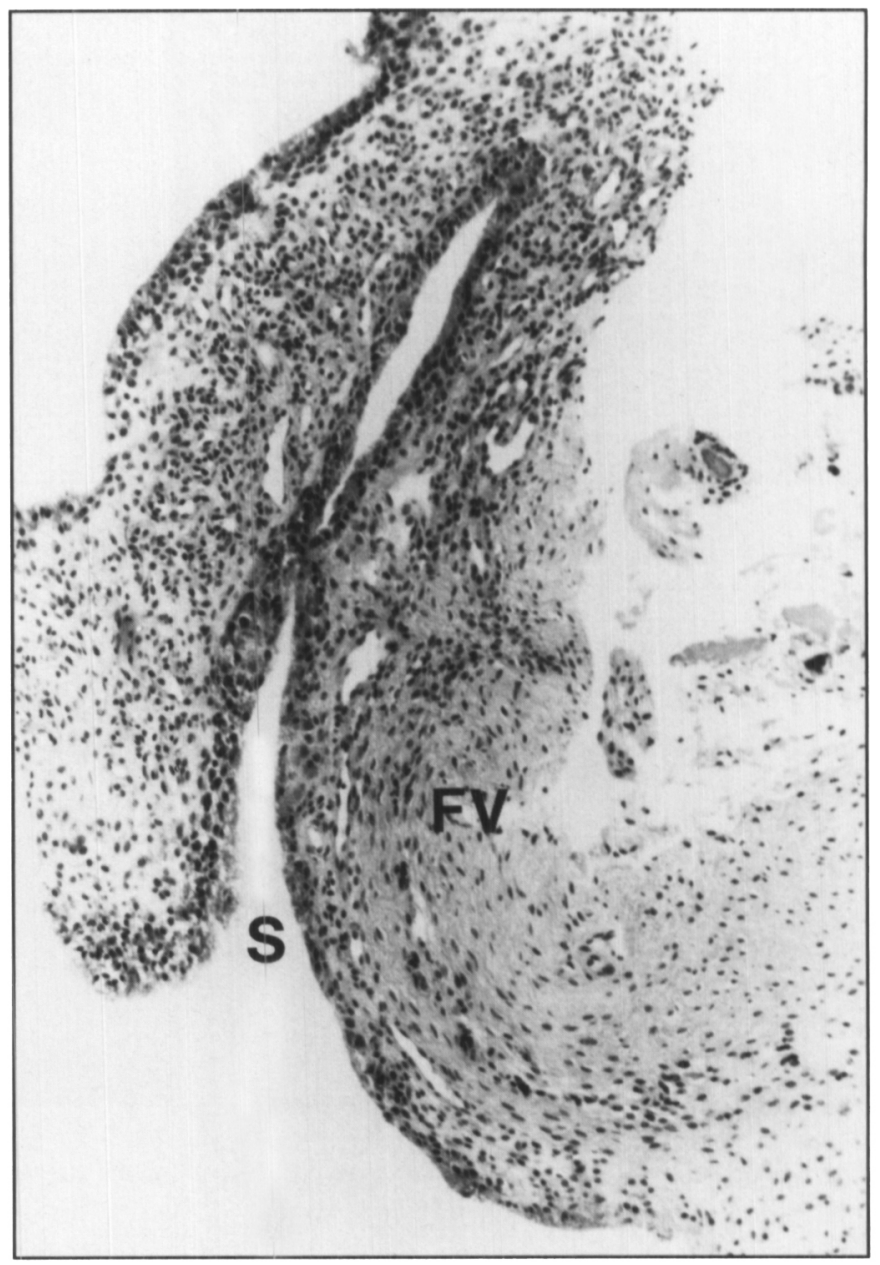

Figure $2 b$ : Occasional specimen fragments show focal areas of synovial-like lining ( $S$ ) over a reactive fibrovascular stroma $(F V)$.

is a matter of some debate. The previously reported cases of periodontoid synovial cysts were managed with a posterior approach. ${ }^{1,2,3}$ This may allow adequate decompression with partial removal of the anteriorly situated mass. However, exposure of the lesion is limited when working around the upper cervical cord. Resection of non-cystic periodontoid degenerative ligamentous lesions has been performed by either anterior ${ }^{27}$ or posterior ${ }^{28}$ approaches. We elected the anterior transoral approach in this case as it provided a direct route to the area of pathology. In order to completely decompress the midline mass, removal of the odontoid process was also performed. This technique may be accomplished without producing atlantoaxial instability. ${ }^{29.30}$ However, close follow-up is required, as delayed instability may develop. ${ }^{30}$ Nevertheless, operative fusions were not performed in previously reported similar cases, ${ }^{12.23 .27 .28}$ and our case also demonstrated no subluxation three months following surgery. This may have resulted from healing of the remaining ligamentous structures, following removal of the inflammatory, degenerative lesion.

Degenerative changes within periodontoid ligaments may result in synovial cyst (ganglion) formation and significant reactive fibrovascular tissue. A high degree of clinical suspicion of cervical medullary compression must be entertained in patients with unusual sensory and motor deficits, especially if associated with neck pain, lower cranial nerve palsies and even intrinsic muscle 


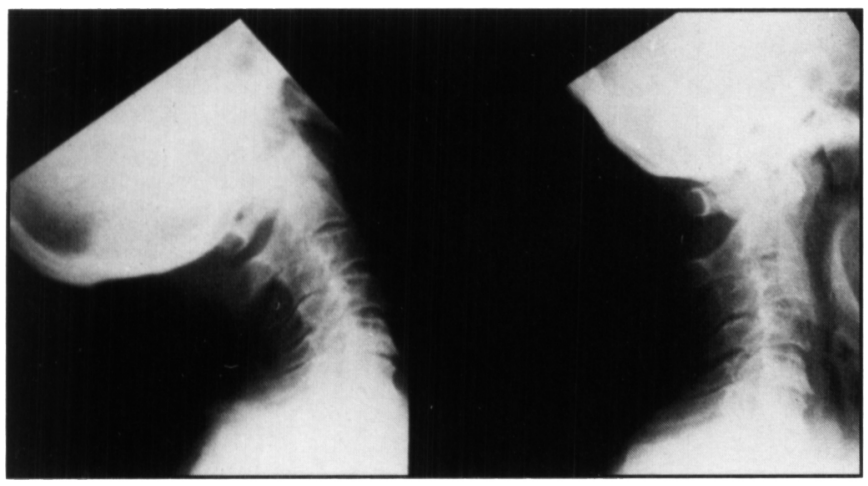

Figure 3a: The preoperative flexion and extension Xrays demonstrate subluxation at the odontooaxial level.

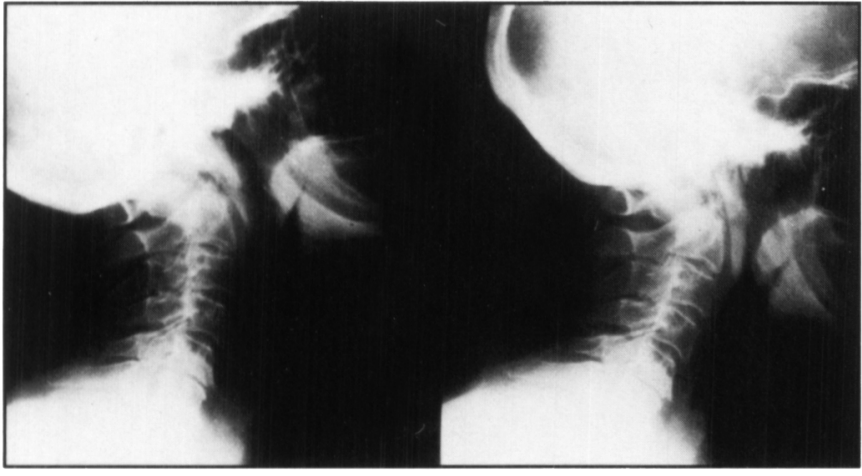

Figure 3b: Followup films three months postoperatively demonstrate good alignment and no further subluxation.

wasting of the hands. Such lesions are best demonstrated by MRI. CT myelography may also be useful when adequate imagimg of the foramen magnum is obtained. However, removal of cerebral spinal fluid by lumbar puncture may produce pressure gradients leading to increased compression of the cervical medullary junction. Assessment of spinal stability is also recommended. Early diagnosis and surgical decompression by the anterior transoral approach may arrest the otherwise progressive neurological deterioration.

\section{ACKNOWLEDGEMENT}

The authors thank Mrs. Karla Patterson and Mrs. Ruth Caldone for their assistance in preparing of the manuscript.

\section{REFERENCES}

1. Goffin J, Wilms G, Plets C, Bruneel B, Casselman J. Synovial cyst at the CI-C2 junction. Neurosurgery 1992; 20(6): 914-916.

2. Miller JD, Al-Mefty O, Middleton TH. Synovial cyst at the craniovertebral junction. Surg Neurol 1989; 31: 239-242.

3. Onofrio BM, Mih AD. Synovial cysts of the spine. Neurosurgery 1988; 22(4): 642-647.

4. Crockard HA, Heilman AE, Stevens JM. Progressive myelopathy secondary to odontoid fractures: clinical, radiological, and surgical features. J Neurosurgery 1993; 78: 579-586.

5. Elsberg CA, Strauss I. Tumors of the spinal cord which project into the posterior cranial fossa. Report of a case in which a growth was removed from the ventral and lateral aspects of the medulla oblongata and upper cervical cord. Arch Neurol Psychiatr 1929; 21: $261-273$.
6. Symonds CP, Meadows SP. Compression of the spinal cord in the neighborhood of the foramen magnum. Brain 1937: 60: 52-84.

7. Bhushan C, Hodges FJ III, Wityk JJ. Synovial cysts (ganglion) of the lumbar spine simulating extradural mass. Neuroradiology 1979: 18: 263-8.

8. Brish A, Payan HM. Lumbar intraspinal extradural ganglion cyst. J Neurol Neurosurg Psychatry 1972; 35; 771-4.

9. Cartwright MJ, Nehls DF, Carrion GC, Spetzler RF. Synovial cyst of a cervical facet joint: case report. Neurosurgery 1985; 16: 850-2.

10. Chen KTK. Synovial cyst of the spinal facet joint. Arch Pathol Lab Med 1983; 107: 100-1

11. Jabre A, Shahbabian S, Keller J. Synovial cyst of the cervical spine. Neurosurgery 1987; 20:316-8.

12. Kao CC, Uihlein A, Bickel WH, Soule EH. Lumbar intraspinal extradural ganglion cyst. J Neurosurg 1968; 29: 168-72.

13. Kao CC, Winkler SS, Turner JH. Synovial cyst of the spinal facet. Case report. J Neurosurg 1974; 41: 372-6.

14. Nijensohn E, Russell EJ, Milan M, Brown T. Calcified synovial cyst of the cervical spine: CT and MR evaluation. J Comput Assist Tomogr 1990; 14: 473-6.

15. Patel SC, Sanders WP. Synovial cyst of the cervical spine. Case report and review of the literature. Am J Neuroradiol 1988; 9: 602-3.

16. Abdullah AF, Chambers RW, Daut DP. Lumbar nerve root compression by synovial cysts of the ligaments flavum. Report of four cases. J Neurosurg 1984; 60: 617: 20.

17. Haase J. Extradural cyst of ligamentum flavum L4 - a case. Acta Orthop Scand 1972; 43: 32-38.

18. Moiel RH, Ehni G, Anderson MS. Nodule of the ligamentum flavum as a cause of nerve root compression. Case report. J Neurosurg 1967; 27: 456-8.

19. Casuccio C, Scapinelli R. Clinical and anatomico-radiological studies of pathological changes in the vertebral spinous processes and adjacent soft tissue. J Bone Joint Surg 1962; 44B: 218.

20. Alquacil-Garcia A. Spinal synovial cyst (ganglion). Review and report of a case presenting as a retropharyngeal mass. Am J Surg Pathol 1987; 11(9): 723-735.

21. Aegerter E, Kirkpatrick JA. Orthopedic Disease: Physiology, Pathology, Radiology. 4th ed. Philadelphia: WB Saunders, 1975; 763-4.

22. Silverberg R. Diseases of the joints. In: Anderson WAD, Kissane JM, eds. Pathology, Vol 7th ed. St. Louis: CV Mosby, 1977; 2041.

23. Herrington $\mathrm{JL} \mathrm{J}$, Edwards LW. Ganglion cysts arising in unusual locations. Ann Surg 1955; 142: 900-3.

24. Kurz LT, Garfin SR, Unger AS, Thorne RP, Rothman RH Intraspinal synovial cyst causing sciatica. J Bone Joint Surg [Am] 1985; 67A: 865-71.

25. Maresca L, Meland NB, Maresca C, Field EM. Ganglion cyst of the spinal canal: case report. J Neurosurg 1982; 57: 140-2.

26. Pendleton B, Carl B, Pollay M. Spinal extradural benign synovial or ganglion cyst: case report and review of the literature. Neurosurgery 1983; 13(3): 322-6.

27. Crockard HA, Sett P, Geddes JF, Stevens JM, Kendall BE, Pringle JAS. Damaged ligaments at the craniocervical junction presenting as an extradural tumor: a differential diagnosis in the elderly. J Neurol Neurosurg Psychiatry 1991; 54: 817-821.

28. Sze F, Brant-Zawadzki MN, Wilson CR, Norman D, Newton TH. Pseudotumor of the craniovertebral junction associated with chronic subluxation: MR imaging studies. Radiology 1986; 161: $391-4$.

29. Crockard HA. The transoral approach to the base of the brain and upper cervical cord. Ann R Coll Surg Engl 1985; 67: 321-325.

30. Dickman CA, Locantro J, Fessler RG. The influence of transoral odontoid resection on stability of the craniovertebral junction. $J$ Neurosurg 1992; 77: 525-30. 